The results presented here indicate that an accumulation of over-production of acetoacetate may upset the normal carbohydrate metabolism. It may interfere either directly, inhibiting the - SH enzymes, or by affecting the glutathione content of the cells. Glutathione, the naturally occurring tripeptide, serves to protect the -SH enzymes of the cells and thus maintains them in an active state. Several enzymes in the beta-cells of the pancreas may also require active sulphydryl groups $^{3}$. If these are involved in insulin synthesis, then acetoacetate at high concentration may inhibit the production of insulin also. Certain observations by Nath and Brahmachari indicate that some such disturbances can be induced by acetoacetate in the production of insulin in the living system.

A detailed report regarding these investigations will be published elsewhere. We are grateful to the Indian Council of Medical Research for the award of a research grant to one of us (V. G. H.).

M. C. Nath

V. G. Hatwalne

Department of Biochemistry,

University, Nagpur. Jan. 3.

' leech, R. S., and Bailey, (. C., J. Biol. Chem., 157, 525 (1945).

" Lopkins, F. G., Morgan, E. J., and T.utwak-Mann, C., Biochem. J., 32, 1829 (1938). Purr, A., Biochem. J., 29, 13 (1935).

${ }^{3}$ Lazarow, A., Physiol. Rev., 29, 48 (1949).

${ }^{4}$ Nath, M. C., and Hatwalne, v. G., Nature, 186, 692 (1950). Nath, M. C. Hatwalne, V. G., and Gadgil, J., S., [Biochem. J., 53, 470 (1953)].

${ }^{5}$ Vath. I. C. and Hatwalne, V. G., Proc. Ind. Sci. Conft. (1950).

- Schneider, W. C., and Potter, V. R., J. Biol. Chem., 149, 217 (1943).

'Nath, M. C., and Brahmachari, H. D., Nature, 157, 336 (1946).

\section{Filter-Paper Disk Chromatography}

IN a recent communication by Proom and Woiwod ${ }^{1}$ commenting on circular paper chromatography, they state: "although the method is admirable for the separation of two or three substances, it is not a satisfactory substitute for large-scale paper chromatography in the separation of more complex mixtures such as protein hydrolysates".

A brief description of this technique was communicated on October 4, 1951, and first published in the November 1951 issue of Current Science ${ }^{2}$. A modification of this technique for the separation and identification of amino-acids was communicated to Nature on November 19, 1951, and published in Nature of May 31, $1952^{3}$. 'The paper by Proom and Woiwod ${ }^{4}$ was published in the October 1951 issue of the Journal of General Microbiology and was received in India early in 1952. We could not, therefore, notice this paper before we communicated ours for publication. It is obvious that our technique was developed independently of Proom and Woiwod's report.

Our experience with this technique for the past one and a half years and the results so far obtained by the application of this technique to the separation of

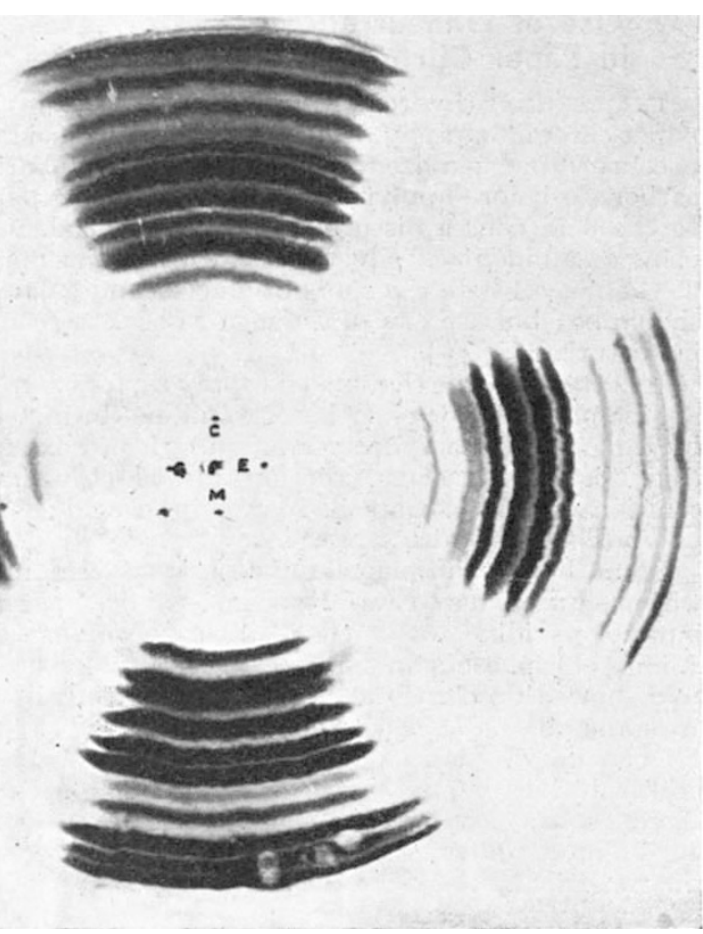

wing the separation of amino-acids present in the hydrolysates of casein $\theta$ destin $\left(\boldsymbol{L}^{T}\right) . M$, mixture of known amino-acids. Whatman No.
$\times 22 \frac{1}{2}$ in. $), n$-butanol - acetic acid - water $(40: 10: 50)$, solvent used. $20 \mu$ l. of hydrolysate $(12 \cdot 5$ per cent nitrogen) spotted

amino-acids in protein hydrolysates show without any doubt that it is well suited to the separation, identification and even quantitative estimation of most of the amino-acids present in protein hydrolysates, as is evident from the papers published by $\mathrm{us}^{5}$. The failure to achieve separation of a large number of amino-acids present in protein hydrolysates by this technique as reported by Proom and Woiwod is probably due to the use of solvents such as $m$-cresol and small-size filter papers $(12.5 \mathrm{~cm}$. diameter $)$ in the investigations reported in their paper. We have been able to separate all the amino-acids present in protein hydrolysates by using $n$-butanol-acetic acidwater $(40: 10: 50)$, pyridine - water $(80: 20)$; and pyridine-amyl acetate -.. water as solvent mixtures. The use of large-size $(35 \mathrm{~cm}$. diameter $)$ filter papers is found to be more advantageous for better resolution. 'The accompanying photograph is of a typical chromatogram showing the separation of: amino-acids present in casein, gelatin and edestin hydrolysates into as many as eleven distinct bands on a large sheet of filter paper $\left(22 \frac{1}{2} \mathrm{in.} \times 18 \frac{1}{4} \mathrm{in.}.\right)$.

The wide application of this technique to the investigation of many problems in this laboratory indicates its value in chromatographic analysis.

K. V. GIRI

Department of Biochemistry,

Indian Institute of Science,

Bangalore 3. Feb. 21.

${ }^{1}$ Proom, H., and Woiwod, A. J., Nature, 171, 12 (1953).

${ }^{2}$ Giri, K. Y., Current Science, 20, 295 (1951).

${ }^{3}$ Giri, K. V., and Rao, N. A. N., Nature, 169, 923 (1952)

${ }^{4}$ Proom, H., and Woiwod, A. J., J. (xan. Microbiology, 5, 681 (19:1). ${ }^{5}$ Giri, K. V., and Rao, N. A. N., J. Ind. Inst. Sci., 34, 95 (1952). Giri, K. V., Krishnamurthy, K., and Venkitasubramanyan, T. A., J. Ind. Inst. Sci., 34, 2)9 (1952). Giri, K. V., Radhakrishnan, A. N., and Vaidyanathan, C. S., Anal. Chem., 24, 1677 (1952). 